\title{
The Incomplete Tricarboxylic Acid Cycle in the Blue-green Alga Anabaena variabilis
}

\author{
By J. PEARCE, C. K. LEACH AND N. G. CARR \\ Department of Biochemistry, University of Liverpool, Liverpool, 3
}

(Accepted for publication 30 October 1968)

SUMMARY

The presence of an incomplete tricarboxylic acid cycle in Anabaena variabilis and Anacystis nidulans is described. These blue-green algae lack both $\alpha$-oxoglutarate dehydrogenase and succinyl-CoA synthetase. Succinyl-CoA was formed in extracts of $A$. variabilis by 3-ketoacyl CoA-transferase using acetoacetyl-CoA as $\mathrm{CoA}$ donor. The activities of the other tricarboxylic cycle enzymes were measured in extracts prepared from autotrophic organisms and from those grown in the presence of acetate. No alterations in activity indicative of enzyme repression or de-repression were observed. These results are discussed in relation to possible reasons for autotrophic behaviour.

\section{INTRODUCTION}

The photosynthetic autotrophically grown blue-green algae have been shown to metabolize acetate (Hoare \& Moore, 1965; Carr \& Pearce, 1966). Although isocitratase and malate synthetase were detected at low activities in extracts of Anacystis nidulans and Anabaena variabilis (Pearce \& Carr, $1967 a$ ), incorporation of $\left[{ }^{14} \mathrm{C}\right]$ acetate into $A$. nidulans gave no evidence for a glycoxylate cycle operation and indicated that the tricarboxylic acid cycle did not proceed further than $\alpha$-oxoglutarate (Hoare, Hoare \& Moore, 1967). The absence of $\alpha$-oxoglutarate dehydrogenase from extracts of $A$. variabilis was reported by Pearce \& Carr $(1967 b)$, and Smith, London \& Stanier (I967) showed that several obligate autotrophs, blue-green algae and chemosynthetic bacteria, lacked $\alpha$-oxoglutarate dehydrogenase and $\mathrm{NADH}_{2}$ oxidase. The latter group also examined the incorporation of $\left[{ }^{14} \mathrm{C}\right]$ acetate by obligate autotrophs and showed that it was transformed into only four amino acids, which were metabolically derived from $\alpha$-oxoglutarate. This restricted flow of $\left[{ }^{44} \mathrm{C}\right]$ carbon from acetate into a limited number of related amino acids had also been reported in 4 . nidulans (Hoare \& Moore, 1965; Hoare et al. 1967) and by Kelly (1967) in Thiobacillus neapolitanus. The present communication presents enzymic evidence for an incomplete tricarboxylic acid cycle in $A$. variabilis and $A$. nidulans, from which $\alpha$-oxoglutarate dehydrogenase and succinyl-CoA synthetase are absent. The role of 3-ketoacyl CoA-transferase in succinyl-CoA formation is described and the failure to adjust enzymic activities after growth in the presence of acetate noted.

\section{METHODS}

Growth and preparation of cell-free extracts. Anabaena variabilis and Anacystis nidulans were grown as previously described (Carr \& Hallaway, I965) on a defined 
mineral-salt medium which was gassed with air + carbon dioxide $(95+5, \mathrm{v} / \mathrm{v})$. Sodium acetate $(20 \mathrm{mM})$ was added to this medium as indicated in the text. After harvesting, organisms were disrupted by ultrasonic treatment as previously described (Pearce \& Carr, 1967a).

Citrate synthase (EC 4.I.3.7) assay. The disappearance of acetyl-phosphate in the presence of $\mathrm{CoA}$ and oxaloacetate was followed by using the procedure of Ochoa (1955). Acetyl-phosphate was estimated as the hydroxamic acid and an appropriate control permitted a correction for the small amount of acetyl-CoA metabolized by de-acylation. This assay utilized the phosphotransacetylase present in extracts of Anabaena variabilis (Pearce \& Carr, I967a).

Aconitase (EC 4.2.I.3) assay. The rate of reduction of NADP in the presence of citrate or cis-aconitate was followed by increase in $E_{340}$ (Ochoa, 1948). Cuvettes contained ( $\mu$ mole): potassium phosphate buffer ( $\mathrm{pH} 7 \cdot 0$ ), $200 ; \mathrm{MgCl}_{2}, 5 ; \mathrm{NADP}, 0.5$; isocitrate dehydrogenase preparation, $50 \mu \mathrm{l}$. (activity, $9 \mu \mathrm{mole} / \mathrm{min} . / \mathrm{ml}$.); cell extract containing 3 to $5 \mathrm{mg}$. protein. The reaction was started by adding substrate (10 $\mu$ mole) to the experimental cuvette.

Isocitrate dehydrogenase (EC I.I.I.42) assay. This enzyme was measured by the procedure of Ochoa (1948).

Glutamate dehydrogenase (EC I.4.I.4) assay. The procedure used depended upon the oxidation of $\mathrm{NADPH}_{2}$ in the presence of $\alpha$-oxoglutarate and observation of decline in $E_{340}$ (Bulen, 1956).

$\alpha$-Oxoglutarate dehydrogenase (EC I .2.4.2) assay. The rate of reduction of NAD or NADP in the presence of $\alpha$-oxoglutarate was measured (Kaufman, Gilvarg, Cori \& Ochoa, 1953). The assay mixture contained ( $\mu$ mole): potassium phosphate buffer (pH 7.0), 200; NAD or NADP, 0.5; cysteine, I0; CoA, 0.05; 3 to $7 \mathrm{mg}$. protein in $2.7 \mathrm{ml}$. total volume. The reaction was started by adding $\alpha$-oxoglutarate ( $20 \mu$-mole) to the experimental cuvette.

Succinic dehydrogenase (EC I.3.99.I) assay. The spectrophotometric assay of Ells (1959) was used.

Succinyl-CoA synthetase (EC 6.2.I.5) assay. Formation of succinyl hydroxamic acid in the presence of hydroxylamine was measured (Kaufman et al. 1953). The following substances ( $\mu$ mole) were incubated at $34^{\circ}$ in test tubes: potassium phosphate buffer ( $\mathrm{pH} 7 \cdot 0$ ), 50; $\mathrm{MgCl}_{2}$, I0; cysteine, 20; CoA, 0.05; ATP, 5; freshly neutralized hydroxylamine hydrochloride, I000; sodium succinate, 200; total volume $2.0 \mathrm{ml}$. The reaction was started by adding cell extract containing 5-10 mg. protein; after incubation the hydroxamate formed was estimated as the ferric chloride complex.

Fumarase (EC 4.2.I.2.) assay. The decline in fumarate concentration, measured by $E_{240}$, was measured according to the procedure of Racker (1950).

Malate dehydrogenase (EC I.I.I.37) assay. The activity of this enzyme was determined by oxidation of $\mathrm{NADH}_{2}$ in the presence of oxaloacetate (Mehler, Kornberg, Grisolia \& Ochoa, 1948).

Malic enzyme (EC I.I.I.40) assay. This enzyme was measured by the procedure of Ochoa, Mehler \& Kornberg, (1948).

3-Ketoacyl CoA-transferase (EC 2.8.3.5) assay. Acetoacetyl-CoA and $\mathrm{Mg}^{2+}$ form a complex with an absorption maximum at $303 \mathrm{~m} \mu$ (Stern, Coon \& del Campillo, I953). Cuvettes contained ( $\mu$ mole): tris ( $\mathrm{pH} 8.5$ ), 200; $\mathrm{MgCl}_{2}$, I0; acetoacetyl-CoA, 0.05; extract (containing I to $5 \mathrm{mg}$. protein); total volume of $3 \mathrm{ml}$. The control cuvette did 
not contain acetoacetyl-CoA, and the reaction was started by adding succinate (Io $\mu$ mole) to each cuvette and the decline in $E_{310}$ measured (Carr \& Lascelles, 196I).

Estimation of protein. The amount of protein present in extracts was determined colorimetrically after removal of the photosynthetic pigments by hot acid ethanol as previously described (Pearce \& Carr, I967a).

Preparation of acetoacetyl-CoA and acetyl-CoA. Acetoacetyl-CoA was synthesized from diketene and CoA by the procedure of Lynen et al. (1958). Acetyl-CoA was prepared from acetic anhydride and CoA by a method based on that of Simon \& Shemin (1953) for succinyl-CoA preparation.

Paper chromatography. Organic acids were identified by co-chromatography with authentic samples in $n$-butanol + acetic acid + water $(60+15+25$ by vol.), ethanol + ammonia + water $(80+5+15)$ and phenol + water + formic acid $(75+25+I)$. Acids were detected as yellow spots on a blue background after dipping the chromatograms in bromocresol green reagent [bromocresol green $(0.1 \%)$ in an ethanol + acetone mixture $(20+81)$ ].

Chemicals. All chemicals were of analytical grade, or of the purest commercial grade available. ATP, ADP, AMP, CoA, ITP, NADP, NADPH ${ }_{2}$, NAD and isocitrate dehydrogenase were purchased from C. F. Boehringer Ltd., Mannheim, Germany; acetyl phosphate from Sigma London Chemical Co. Ltd., Lettice Street, London, S.W.6. Diketene was kindly supplied by the Department of Organic Chemistry, University of Liverpool.

\section{RESULTS}

Cell-free extracts of Anabaena variabilis contained most of the tricarboxylic acid cycle enzymes at comparable degrees of activity. Succinic dehydrogenase was present but the activity was less than one tenth that of the other enzymes found. $\alpha$-Oxoglutarate dehydrogenase and succinyl-CoA synthetase were not detected in any extract of A. variabilis or Anacystis nidulans (Table I). Aconitase activity was significantly greater with cis-aconitate than with citrate as substrate. Experimental controls showed

Table I. Tricarboxylic acid cycle and some associated enzymes in extracts of Anabaena variabilis

Activities are expressed as $\mathrm{m} \mu \mathrm{mole} / \mathrm{min} . / \mathrm{mg}$. protein, and are the mean of several determinations. nt, not tested.

Enzyme

Citrate-condensing enzyme

Aconitase (citrate as substrate)

Aconitase (cis-aconitate as substrate)

Isocitrate dehydrogenase

$\alpha$-Oxoglutarate dehydrogenase

Succinic thiokinase

Succinic dehydrogenase

Fumarase

Malate dehydrogenase

Glutamate dehydrogenase

Malic enzyme

3-Ketoacyl-CoA transferase

$\begin{array}{cc}\mathrm{CO}_{2} & \begin{array}{c}\mathrm{CO}_{2}+\text { ace- } \\ \text { tate }(20 \mathrm{mM})\end{array} \\ 5.7 & 6 . \mathrm{I} \\ 2 . \mathrm{I} & \mathrm{nt} \\ \mathrm{II} .9 & \text { nt } \\ 4.7 & 5.0 \\ 0 & 0 \\ 0 & 0 \\ 0.2 & 0.2 \\ 3.7 & 3.5 \\ 2.0 & 2.3 \\ 2.7 & 2.4 \\ 2.0 & 2.3 \\ 2.5 & \mathrm{nt}\end{array}$


that aconitase was not present in the commercial preparation of isocitrate dehydrogenase used in the aconitase assay procedure. The isocitrate dehydrogenase in extracts of $A$. variabilis was specific for NADP, there being no activity with NAD as coenzyme. After the addition to the reaction mixture of ( $5 \mu$ mole) AMP or ADP no alteration in the rate with NADP was observed and NAD was still inactive. Glutamate dehydrogenase activity in these extracts was also specific for NADP, as was the conversion of malate to pyruvate and carbon dioxide by the malic enzyme.

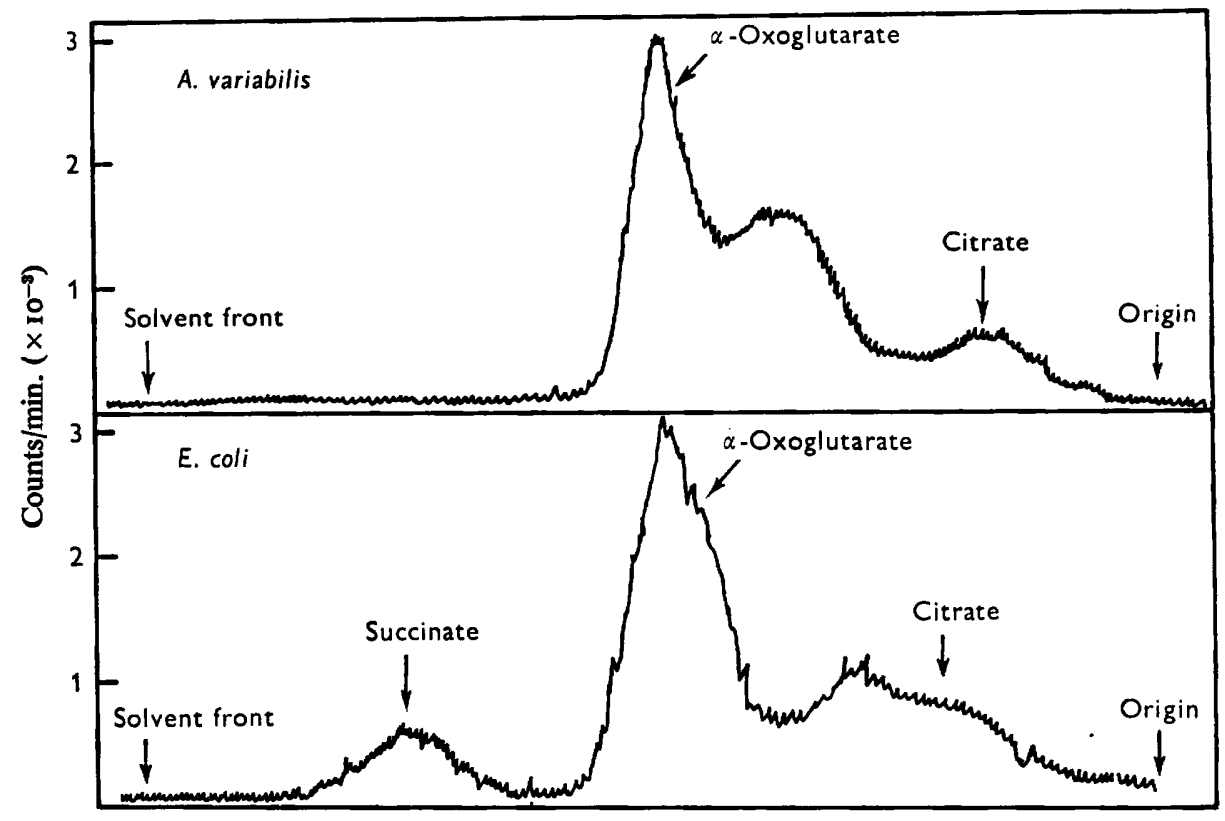

Fig. I. Products obtained after incubation of $\left[5{ }^{-14} \mathrm{C}\right] \alpha$-oxoglutarate (Io $\mu$ mole containing $10 \mu \mathrm{c})$ in the presence of the Anabaena variabilis extract $(8 \mathrm{mg}$. protein) for $20 \mathrm{~min}$. and Escherichia coli extract ( $5 \mathrm{mg}$. protein) for $8 \mathrm{~min}$. under the conditions used for the $\alpha$-oxoglutarate dehydrogenase assay (see Methods). Products were separated by paper chromatography (butanol + acetic acid + water, $60+15+25$ by vol). and radioactive compounds detected by a Nuclear-Chicago Actigraph III chromatogram scanner. Compounds were identified by co-chromatography with authentic samples (see Methods).

The slow rate of succinate oxidation by extracts of Anabaena variabilis was not increased by adding back pellet fraction to the cell-free extract; the activity of succinic dehydrogenase was of the same order as that of isocitrate lyase (Pearce \& Carr, 1967a). Neither $\alpha$-oxoglutarate dehydrogenase nor succinyl-CoA synthetase were detected in extracts of the two blue-green algae examined. Different $\mathrm{pH}$ values of the assay procedure and the addition of thiamine pyrophosphate, lipoic acid and FAD singly or together did not permit detection of the former enzyme, which was readily shown, using the identical procedure, in extracts of Escherichia coli. The absence of $\alpha$-oxoglutarate dehydrogenase in $A$. variabilis was confirmed by examination of the products of $\left[5^{14} \mathrm{C}\right] \alpha$-oxoglutarate incubation. The incubation mixture was that of the $\alpha$-oxoglutarate dehydrogenase assay system (see Methods) with the addition of ${ }^{14} \mathrm{C}$-labelled substrate. After anaerobic incubation at $34^{\circ}$ the reaction was ended by the addition 
of hot ethanol ( $20 \mathrm{ml}$.). After further extraction with ethanol the combined extracts were reduced in volume by rotary distillation under low pressure at $40^{\circ}$ and products separated by paper chromatography (Fig. 1). Although citrate and glutamate were produced from $\left[5^{-14} \mathrm{C}\right] \alpha$-oxoglutarate, no succinate, malate or fumarate were found after varied incubation times ( 15 to $120 \mathrm{~min}$.). This was in contrast to the results of an identical experiment with $E$. coli in which $\left[{ }^{14} \mathrm{C}\right]$ succinate was readily detected.

The activation of succinate to succinyl-CoA could be not accomplished directly in extracts of Anabaena variabilis or Anacystis nidulans in spite of replacement of ATP with GTP or ITP, although enzymes necessary for acetate activation were present in such extracts (Pearce \& Carr, 1967a). Succinyl-CoA formation by a 3-ketoacyl CoAtransferase from acetoacetyl-CoA and succinate was detected; the addition of succinate, in the presence of cell free extract of $A$. variabilis, produced a marked decline in

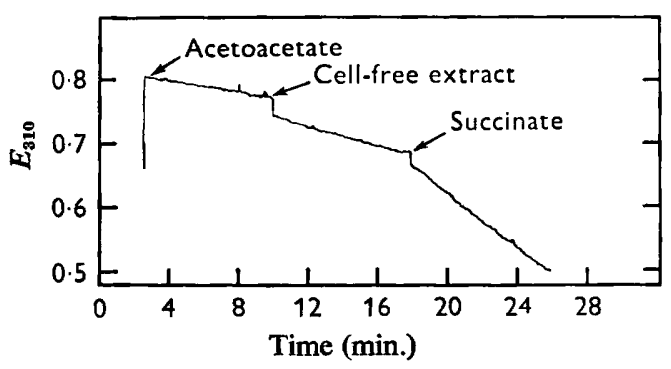

Fig. 2

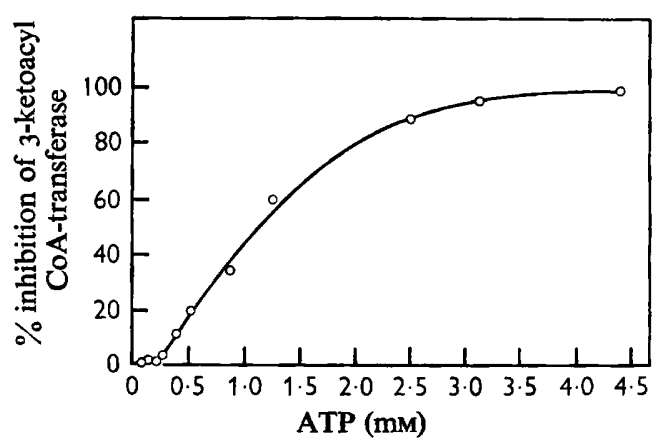

Fig. 3

Fig. 2. 3-Ketoacyl CoA-transferase in extracts of Anabaena variabilis was measured by the decline in $E_{310}$, due to an acetoacetyl-CoA $+\mathrm{Mg}^{2+}$ complex, in the presence of succinate. The assay was done at room temperature $\left(20^{\circ}\right)$ in a Unicam SP 700 recording spectrophotometer (see Methods), additions to the cuvettes were as shown.

Fig. 3. The inhibition of 3-ketoacyl CoA-transferase, in extracts of Anabaena variabilis, by increasing amounts of ATP. Results are expressed as the \% inhibition of enzyme activity, measured as in Methods except that ATP was added as shown.

the acetoacetyl-CoA $+\mathrm{Mg}^{2+}$ complex measured by a decrease in $E_{310}$, corresponding to a rate of $2.5 \mathrm{~m} \mu \mathrm{mole} / \mathrm{min}$./mg. protein (Fig. 2). This enzyme was not sedimented by centrifugation for $2 \mathrm{hr}$ at $75,000 \mathrm{~g}$ and was stable for 2 weeks at $-18^{\circ}$. 3-Ketoacyl CoA-transferase was inhibited by ATP (Fig. 3), the sigmoidal kinetics of this inhibition being indicative of an allosteric interaction. AMP and ADP were also inhibitory but at Io-fold higher concentration and with no evidence of sigmoidal kinetics. The 3-ketoacyl CoA-transferase was specific for acetoacetyl-CoA; acetyl-CoA was only $\mathrm{I} \%$ as effective as a CoA donor.

An important feature of enzyme activities concerned in tricarboxylic acid metabolism in Anabaena variabilis was the failure of the organism to adjust enzymic content following the inclusion of acetate $(20 \mathrm{~mm})$ in growth medium. There was no increase in activity of any of the tricarboxylic acid cycle enzymes, nor of the associated malic enzyme and glutamate dehydrogenase in extracts grown in the presence of acetate (Table I). Previous work had shown that, under the conditions used, acetate was significantly incorporated and assimilated into $A$. variabilis (Pearce \& Carr, 1967a). 


\section{DISCUSSION}

Enzymes present in extracts of Anabaena variabilis would permit the operation of an incomplete tricarboxylic acid cycle, as illustrated in Fig. 4. The absence of $\alpha$-oxoglutarate dehydrogenase and succinyl-CoA synthetase activity prevents cyclic flow, and this is consistent with the entry of $\left[{ }^{14} \mathrm{C}\right]$ acetate into only a limited number of amino acids, first observed by Hoare \& Moore (I965). The synthesis of oxoloacetate, and hence the aspartate family of amino acids, could arise from the carboxylation of pyruvate or phosphoenol pyruvate. Some formation of succinate would be possible

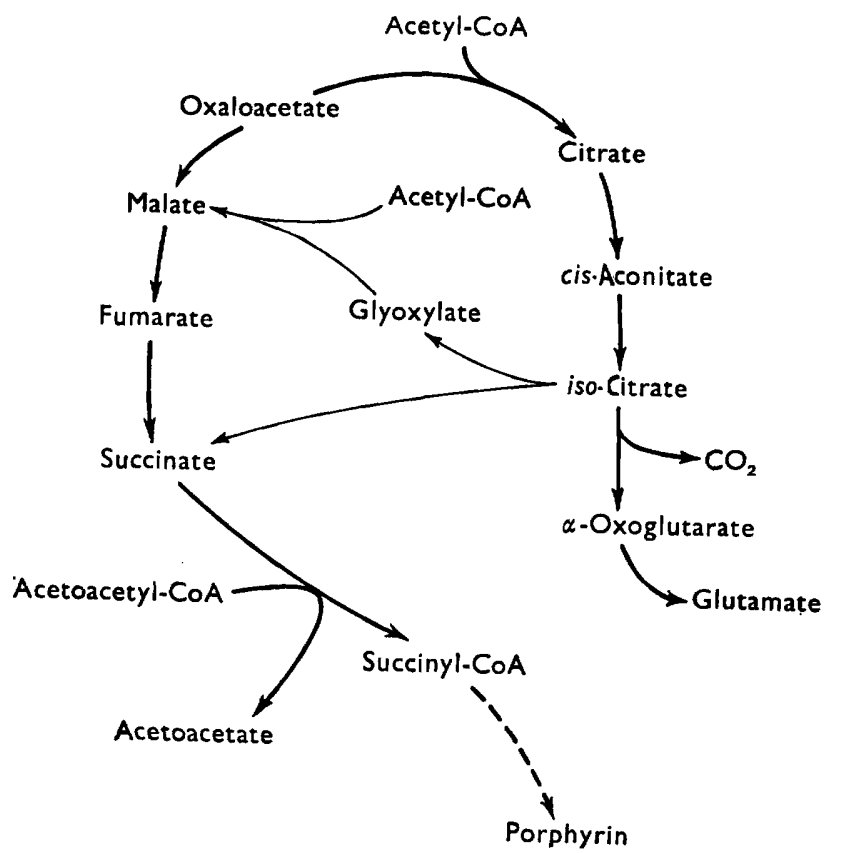

Fig. 4. The interrupted tricarboxylic acid cycle in Anabaena variabilis.

by the activity, detected at low levels, of the glyoxylate cycle enzymes (Pearce \& Carr, I967a). The activation of succinate to succinyl-CoA, necessary for all porphyrin formation, did not proceed directly but by a transferase enzyme from acetoacetyl-CoA, which was allosterically inhibited by ATP. Isocitrate dehydrogenase in extracts of A. variabilis required NADP as coenzyme and there was no evidence of activation by AMP or ADP, as is found with the NAD specific enzyme in other organisms (Kornberg \& Pricer, I95I ; Hathaway \& Atkinson, 1963). This lack of stimulation is consistent with a biosynthetic, rather than energy-yielding, function of this enzyme. Both glutamate dehydrogenase and the malic enzyme, in $A$. variabilis, were also specific for NADP.

The production of $\left[{ }^{14} \mathrm{C}\right]$ carbon dioxide from carboxyl-labelled acetate by Anabaena variabilis was readily shown whereas the methyl-carbon contributed only very slightly to respiratory carbon dioxide (Pearce \& Carr, 1967a). The release of carbon dioxide from the $\left[\mathrm{I}^{14} \mathrm{C}\right]$ position of acetate presumably arises from the metabolism of $\alpha$-oxoglutarate, via glutamate or through the operation of a glyoxylate cycle. 
An incomplete tricarboxylic acid cycle lacking $\alpha$-oxoglutarate has been reported in two photosynthetic bacteria, Chloropseudomonas ethylicum (Callely, Rigopoulos \& Fuller, 1968) and Chromatium D (Fuller, Smillie, Sisler \& Kornberg, 196I). The interruption of the cycle at the point of $\alpha$-oxoglutarate not only deprives the organism of a site of substrate level phosphorylation, but severely curtails the formation of reduced pyridine nucleotides by oxidation of organic substrates. Smith et al. (1967) suggested that the absence of $\alpha$-oxoglutarate dehydrogenase and of $\mathrm{NADH}_{2}$ oxidase are the lesions in metabolism that cause an organism to be an obligate autotroph. The break in the tricarboxylic acid cycle could be alleviated by the exogenous supply of $\mathrm{C}_{4}$ intermediates, and the latter workers place particular emphasis on the absence of $\mathrm{NADH}_{2}$ oxidase which would prevent the organism from linking, via an electron transport chain, oxidation of organic substrates to ATP generation. However, Hempfling \& Vishniac (1965) reported an $\mathrm{NADH}_{2}$ oxidase in extracts of the obligate autotroph Thiobacillus neapolitanus and Trudinger \& Kelly (1968) recorded the reduction of endogenous cytochrome $c$ by $\mathrm{NADH}_{2}$ in the same organism. The presence of $\mathrm{NADPH}_{2}$ oxidase in extracts of several obligate autotrophic blue-green algae has also been measured (Leach \& Carr, I968).

A feature of the data presented in this communication is the absence of any alteration in enzymic activities measured after inclusion of acetate in the growth medium. Tricarboxylic acid cycle enzymes in certain other micro-organisms are markedly affected by the growth medium, inclusion of acetate increased activity generally in Hydrogenomonas sp. (Trüper, 1965) and Aerobacter aerogenes (Forget \& Pichinoty, 1967). The activity of isocitrate dehydrogenase was several fold greater after growth of Escherichia coli and Pseudomonas aeruginosa on acetate rather than glucose (Pearce \& Carr, unpublished). In other aspects of intermediary metabolism Anabaena variabilis has been shown not to exercise control over enzyme biosynthesis but only on existing enzyme molecules by end-product interaction (Carr, 1967; Pearce \& Carr, 1967a; Pearce \& Carr, 1968; Hood \& Carr, 1968). The failure of $A$. variabilis and other bluegreen algae to increase growth rate in the presence of substrates known to be assimilated and metabolized could be due, at least in part, to lack of control at the transcription level. We suggest that this lack of control may be a characteristic and causative feature of obligate autotrophs.

These studies were supported by the Science Research Council; J.P. acknowledges the receipt of a Liverpool University Research Studentship and C.K.L. of a Science Research Council Research Studentship.

\section{REFERENCES}

BULEN, W. A. (1956). The isolation and characterization of glutamic dehydrogenase from corn leaves. Archs Biochem. Biophys. 62, 173.

Callely, A. G., Rigopoulos, N. \& Fuller, R. C. (1968). The assimilation of carbon by Chloropseudomonas ethylicum. Biochem. J. 106, 615.

CARR, N. G. (1967). Aspects of enzymic control in blue-green algae. Abstr. 5th Meeting Fedn. Europ. Biochem. Soc., Universitetsforlaget, Oslo, p. 89.

CarR, N. G. \& Hallaway, M. H. (1965). Reduction of phenolindo-2,6-dichlorophenol in dark and light by the blue-green alga, Anabaena variabilis. J. gen. Microbiol. 39, 335.

CARR, N. G. \& Lascelles, J. (1961). Some enzymic reactions concerned in the metabolism of acetoacetyl-coenzyme A in Athiorhodaceae. Biochem. J. 80, 70. 
CARr, N. G. \& Pearce, J. (1966). Photoheterotrophism in blue-green algae. Biochem. J. 99, 28 P.

ELLS, H. A. (1959). A colorimetric method for the assay of soluble succinic dehydrogenase and pyridine nucleotide-linked dehydrogenase. Archs Biochem. Biophys. 85, 56I.

Forget, P. \& Pichinoty, F. (1967). Le cycle tricarboxylique chez Aerobacter aerogenes. Annls Inst. Pasteur, Paris I12, 26I.

Fuller, R. C., SMILlie, R. M., Sisler, E. C. \& Kornberg, H. L. (I96I). Carbon metabolism in Chromatium. J. biol. Chem. 236, 2140.

Hathaway, J. A. \& Atkinson, D. E. (1963). The effect of adenylic acid on yeast nicotinamide adenine dinucleotide isocitrate dehydrogenase, a possible metabolic control mechanism. J. biol. Chem. 238, 2875.

Hempfling, W. P. \& Vishniac, W. (1965). Oxidative phosphorylation in extracts of Thiobacillus. Biochem. Z. 342, 272.

HOARE, D. S. \& MOORE, R. B. (1965). Photoassimilation of organic compounds by autotrophic bluegreen algae. Biochim. Biophys. Acta 109, 622.

HoARE, D. S., HoARe, S. L. \& MOORE, R. B. (1967). The photoassimilation of organic compounds by autotrophic blue-green algae. J. gen. Microbiol. 49, $35 \mathrm{I}$.

HooD, W. \& CARR, N. G. (I968). Threonine deaminase and acetolactate synthetase in Anabaena variabilis. Biochem. J. I09, 4 P.

Kaufman, S., Gillarg, C., CORI, O. \& OChOA, S. (1953). Enzymatic oxidation of $\alpha$-ketoglutarate and coupled phosphorylation. J. biol. Chem. 203, 869.

KELLY, D. P. (1967). The incorporation of acetate by the chemoautotroph Thiobacillus neapolitanus strain c. Arch. Mikrobiol. 58, 99.

KORNBERG, A. \& Pricer, W. E. (I95I). Di- and triphosphopyridine nucleotide isocitric dehydrogenase in yeast. J. biol. Chem. $189,123$.

LEACH, C. K. \& CARR, N. G. (I968). Reduced nicotinamide adenine dinucleotide phosphate oxidase in the autotrophic blue-green alga, Anabaena variabilis. Biochem. J. ro9, 4 P.

Lynen, F., Henning, U., Bublitz, C., Sorbo, B. \& Kröplin-Rueff, L. (1958). Der chemische Mechanismus der Acetessigsäurebildung in der Leber. Biochem. Z. 330, 269.

Mehler, A. H., Kornberg, A., Grisolia, S. \& OchoA, S. (1948). The enzymatic mechanism of oxidation reductions between malate or isocitrate and pyruvate. J. biol. Chem. 174, 96I.

OchоA, S. (1948). Biosynthesis of tricarboxylic acids by carbon dioxide fixation. J. biol. Chem. I74, 133.

OchоA, S. (1955). Crystalline condensing enzyme from pig heart. Meth. Enzymol. x, 685.

OchoA, S., Mehler, A. H. \& Kornberg, A. (1948). Biosynthesis of dicarboxylic acids by carbon dioxide fixation. J. biol. Chem. r74, 979.

PeARCE, J. \& CARR, N. G. (1967a). The metabolism of acetate by the blue-green algae, Anabaena variabilis and Anacystis nidulans. J. gen. Microbiol. 49, 301.

PeARCE, J. \& CARR, N. G. (1967b). An incomplete tricarboxylic acid cycle in the blue-green alga, Anabaena variabilis. Biochem. J. 105, 45 P.

PeARCE, J. \& CARR, N. G. (1968). The incorporation and metabolism of glucose by Anabaena variabilis. J. gen. Microbiol. 54, 45I.

RACKER, E. (1950). Spectrophotometric measurement of the enzymatic formation of fumaric and cisaconitic acids. Biochim. biophys. Acta 4, 21 I.

Simon, E. J. \& Shemin, D. (1953). The preparation of S-succinyl coenzyme A. J. Am. chem. Soc. 75, 2520.

SMtth, A. J., London, J. \& STANIER, R. Y. (1967). Biochemical basis of obligate autotrophy in bluegreen algae and thiobacilli. J. Bact. $94,972$.

Stern, J. R., CoOn, M. J. \& Del CAMPIllo, A. (I953). Acetoacetyl coenzyme A as intermediate in the enzymatic breakdown and synthesis of acetoacetate. J. Am. chem. Soc. 75, 1517.

Trudinger, P. A. \& Kelly, D. P. (1968). Reduced nicotinamide adenine dinucleotide oxidation by Thiobacillus neopolitanus and Thiobacillus strain C. J. Bact. 95, 1962.

TRÜPER, H. G. (1965). Tricarboxylic acid cycle and related enzymes in Hydrogenomonas strain H I6 G+ grown on various carbon sources. Biochim. biophys. Acta III, 565. 